Rev. Latinoam. Psicopat. Fund., São Paulo, v. 11, n. 4, p. 726-734, dezembro 2008 (Suplemento)

\title{
Fontes e debates em torno da saúde do escravo no Brasil do século XIX*
}

Ângela Pôrto

Este trabalho apresenta uma amostragem da produção acadêmica recente sobre a saúde do escravo no Brasil e os debates e tendências atuais sobre a questão. Enfocam-se tanto os atuais trabalhos da área de História como as principais fontes disponíveis sobre a questão até agora reunidas pela pesquisa, que coordeno na Casa de Oswaldo Cruz/Fiocruz. A pesquisa busca reunir essas fontes, organizando-as em um banco de dados, que será brevemente disponibilizado publicamente.

Palavras-chave: História da Saúde, escravidão, bibliografia, Brasil

* Versão modificada e ampliada de trabalho apresentado no XIV Congreso de la Sociedad Española de Historia de la Medicina, na mesa temática "Males e infortunios de la esclavitud: visiones sobre las enfermedades de los negros esclavos en América". Granada, 11 a 14 de junho de 2008. 
Observamos na historiografia brasileira que a questão da saúde e da doença do escravo tem sido analisada apenas indiretamente nos trabalhos acadêmicos sobre a escravidão em geral e que os múltiplos aspectos relacionados a essa questão são apenas parcialmente conhecidos, além de se encontrarem dispersos em fontes primárias de diversas origens. Este quadro, no entanto, tem mudado nos últimos anos. Teses recentes encontram no estudo das práticas de saúde, doença e cura um espaço de interessante valor histórico para a observação das tensões, conflitos e negociações na sociedade escravista, ver por exemplo em Witter (2007) a negociação das liberdades permeada pelas questões de saúde, e em Sampaio (2001) e Pimenta (2003) a convivência e os conflitos entre terapêuticas. Novos programas de pesquisa desenvolvem-se hoje com vistas a explicar as percepções historiográficas da escravidão, como os freqüentes Encontros de Escravidão e Liberdade no Brasil Meridional e os cada vez mais numerosos Simpósios Temáticos voltados para escravidão, organizados em Congressos de História; publicações de divulgação de pesquisas como CD-ROM (Porto, ed. 2007) e Guia Bibliográfico (Xavier, 2007) e Cursos, como o de "Doenças e Escravidão: sistema de saúde e práticas terapêuticas”, no Programa de PósGraduação em Ciências da Saúde da Casa de Oswaldo Cruz/Fiocruz. Todos esses empreendimentos visam abrir novos caminhos para temas como a saúde física e mental do escravo. Vale lembrar que nos últimos anos, temas como suicídio e doença mental ganharam destaque, ver por exemplo Oda (2007), Lorenzo (2007) e Oliveira (2007 e 2008), entre outros. O trabalho que desenvolvemos na Casa de Oswaldo Cruz tem buscado reunir fontes e pesquisas que dêem devida visibilidade ao tema da saúde na história da escravidão, organizando-as em um banco de dados, que será brevemente disponibilizado. Desde março de 2006 iniciamos o projeto "Sistema de saúde do escravo no Brasil do século XIX: instituições, doenças e práticas terapêuticas”, que realiza uma série de atividades com vistas a estimular pesquisas sobre essa temática. Além de realizar tal síntese historiográfica, nosso objetivo principal tem sido 
analisar o pensamento médico em torno da escravidão, a partir das teses médicas defendidas na Faculdade de Medicina do Rio de Janeiro e da Bahia e dos periódicos médicos, que elegeram temáticas ligadas à escravidão e à doença associada ao tráfico. Buscamos verificar a hipótese da existência de uma tradição específica do pensamento médico brasileiro e a associação de certas doenças ao tráfico de escravos, como expressão da trajetória histórica de uma sociedade marcada pela escravidão.

O século XIX registrou o maior número de entradas de escravos africanos no Brasil e, ao mesmo tempo, das tentativas para a eliminação do chamado "comércio infame”. Foi também nas primeiras décadas do século XIX, que se deu a criação da Sociedade de Medicina no Rio de Janeiro, depois denominada Academia Imperial de Medicina e das faculdades de medicina do Rio de Janeiro e Bahia, anteriormente academias médico-cirúrgicas, assim como o aparecimento de diversos periódicos dedicados à propagação do conhecimento médico. Sobre as instituições médicas ver Edler (2003) e sobre os periódicos ver Ferreira (1999). Em meio às discussões travadas em torno da abolição do tráfico de escravos, a institucionalização da medicina levou à produção de trabalhos sobre as principais doenças que acometiam a população, datando dessa época os primórdios dos estudos sobre as chamadas doenças africanas. Doenças como a febre amarela e a sífilis foram atribuídas ao tráfico nas teses produzidas entre 1835 e 1855, como verificaram Zampa e Kodama (2007). A atribuição de determinadas doenças aos povos provenientes da África é um assunto que está presente no pensamento médico até os nossos dias, e cuja argumentação se consolidou com os estudos clássicos de Rodrigues (2004) e Freitas (1935). O objetivo da pesquisa de Kaori Kodama, na Casa de Oswaldo Cruz/Fiocruz, é analisar as coordenadas mais gerais do pensamento médico brasileiro, relacionado à problemática da escravidão, das raças e da constituição de um modelo de nação, ressaltando-se os discursos sobre doenças dos escravos, ou de origem africana.

A higiene do escravo e as doenças que mais os acometiam foram tema de teses, manuais, tratados e artigos em periódicos médicos especializados. Os manuais dedicados aos proprietários de escravos têm claro intuito civilizador e, mais do que prescrever terapêuticas, seus autores se dedicam a aconselhar condutas morais e a educar higienicamente. A partir do relato das enfermidades, os autores orientam os senhores no trato de sua escravaria, arrolando doenças, causas, tratamento e cuidados no processo curativo e preventivo de enfermidades mais comuns. Ver, por exemplo, os manuais de Imbert (1834), Fonseca (1863) e Taunay (1839); o capítulo III, dedicado às enfermidades dos negros, do clássico tratado de Sigaud (1844); e os dicionários médicos de Chernoviz (1890) e Langgaard (1873), que trazem observações específicas quanto aos negros. 
Quanto às teses das faculdades de medicina, apenas quatro teses elegendo a temática "higiene do escravo" foram defendidas no Rio de Janeiro: Jardim (1847), Duarte (1849), Souza (1851) e Teuscher (1853). Na Bahia, nenhuma tese elegeu essa temática; o assunto é, porém, abordado em trabalhos que não têm o escravo como foco principal. O negro africano, escravo ou não, estará referido em inúmeras teses de ambas as faculdades. Como observa Silvio Lima, doutorando do Programa de Pós-Graduação em História das Ciências da Saúde, a partir de levantamentos cuidadosos de artigos e teses do século XIX, existe uma considerável produção intelectual que aborda o tema "o negro e as doenças procedentes da África”. Além disso, ao relacionar os africanos, cativos ou libertos, a determinadas doenças, médicos e cirurgiões produzem inúmeros relatos nos periódicos médicos, originários da observação de doenças em negros. Para citar alguns desses jornais: O Atheneo: periódico científico e literário dos estudantes da escola Médica da Bahia; Archivo Médico Brasileiro: gazeta mensal de medicina, cirurgia e sciencias accessorias e Jornal da Academia Médico-Homeopática do Brasil; todos publicados entre os anos 1840 e 1850 do século XIX.

Igualmente, com o objetivo de estimular a discussão e as perspectivas de novas abordagens sobre a vida higiênica dos escravos no Brasil, efetuamos o levantamento e análise do conjunto documental do Arquivo da Santa Casa de Misericórdia do Rio de Janeiro e da Bahia, única instituição a prestar atendimento hospitalar aos escravos até a primeira metade do século XIX e responsável pelos sepultamentos. A Santa Casa é a administradora dos cemitérios públicos, desde que foram criados, em 1851, tendo recebido, desde 1831, com o encerramento do cemitério dos Pretos Novos, os cadáveres de africanos livres e escravos para sepultamento no Cemitério da Misericórdia. Guarda, portanto, farta documentação sobre óbitos de escravos.

Jorge Prata de Sousa (2003) já observou, a respeito dos registros de óbitos dos cemitérios públicos administrados pela Santa Casa, que:

Esses manuscritos são ricos em detalhes, oferecem informações sobre as causas mortis, o nome do falecido, condição jurídica e estado conjugal, idade, ofício e endereço (...) obedecem a uma sistemática, possuindo estrutura fixa e natureza serial. Possibilitam comparar óbitos de escravos com de livres, forros e africanos livres; mapear as causas de morte; observar a sazonalidade de algumas doenças epidêmicas; calcular índices de mortalidade por sexo, idade, nacionalidade; e a distribuição de escravos por proprietários. Além desses itens pode-se ainda analisar a nomenclatura das doenças como expressão de um sistema classificatório que reflete o conhecimento da patologia clínica da época. (p. 35)

Pretendemos, ao divulgar a documentação dos Hospitais da Santa Casa, abrir caminhos para a pesquisa em história da saúde dos escravos no Brasil e forne- 
cer um aspecto um pouco mais amplo do tratamento das doenças em escravos, fazendo uso não apenas dos registros de óbitos, mas de variada documentação. Os resultados demonstrados por Karasch (2000), em seu estudo até hoje incomparável, sobre a vida dos escravos no Rio de Janeiro, baseia-se fundamentalmente na documentação desse mesmo arquivo. Sabemos que, ao contrário da Santa Casa de Misericórdia da Bahia, na cidade de Salvador, a documentação hospitalar não foi preservada no Rio de Janeiro. A tese de Renilda Barreto (2005) fez uso de farta documentação hospitalar da Misericórdia da Bahia. Ver também os trabalhos apresentados em simpósios por Tânia Pimenta (2007) e Ângela Porto (2007). Com exceção de notas de despesas e alguns mapas sobre o movimento de doentes no hospital, pouco temos para traçar a história das doenças ou dos doentes a partir de documentos médicos de origem na Santa Casa do Rio de Janeiro.

O trabalho realizado no Arquivo da Misericórdia do Rio de Janeiro compreendeu, inicialmente, uma avaliação geral da documentação disponível. Verificamos que os documentos relacionados aos cemitérios são os que melhor se conservaram, e os relacionados aos Hospitais da Irmandade hoje se restringem basicamente às documentações financeiras e administrativas. Os Livros de Registro de Óbitos são, portanto, a série documental mais completa e seus dados foram sistematizados em fichas, para permitir seu tratamento eletrônico de maneira padronizada.

Para concluir, constatamos que, no plano das atuais pesquisas na área de História, observa-se a renovada discussão do tema da escravidão associada ao pensamento médico e às práticas médicas e de cura no Brasil. Essas pesquisas beneficiam-se também de estudos mais aprofundados sobre a história da cultura africana, história das religiões e análises apoiadas em abordagens antropológicas (Slenes, 1995 e 1999), como a questão das identidades étnicas, hoje um tema largamente explorado. Ver, por exemplo, recente estudo de Faria, Gomes e Soares (2003) e demais trabalhos desses autores. As novas produções vêm caminhando em direções variadas quando se aborda a questão da raça ou da saúde dos escravos. Soma-se a estas as atuais abordagens em estudos demográficos, que privilegiam os estudos sobre família escrava e relações de compadrio; ver, por exemplo, Florentino (1995) e Florentino e Góes (1997). As condições de vida e morte dos escravos são hoje revistas pelos estudos sobre a dieta alimentar dos africanos cativos, sobre a experiência da travessia atlântica pelo tráfico negreiro, assim como pelas teorias sobre biodiversidade e migração de populações. Sobre essas novas abordagens ver Cristina Wissenbach, que trata da necessidade da adoção dessa perspectiva para a análise das doenças em escravos e Diana Maul, que aborda a questão da migração de doenças, ambas em Porto (Ed., 2007).

Em síntese, esta comunicação propôs-se a apresentar uma amostragem da produção acadêmica recente sobre a saúde do escravo no Brasil e enfocar tanto 
os atuais trabalhos da área de História como as principais fontes disponíveis sobre a questão até agora reunidas pela pesquisa. Consideramos que as pesquisas sobre a experiência cultural e biológica que os escravos trouxeram para a América, bem como sobre as condições que aqui encontraram, expandem o entendimento sobre a contribuição africana para a história americana. Aspectos da diversidade social e cultural, na linguagem, religião, alimentação, vestuário, habitação e relações familiares, hierárquicas e de trabalho, devem ser explorados. Não menos importante é considerar quais seriam os instrumentos de culturais que os escravos lançaram mão para enfrentar sua nova vida, suas estratégias de inserção na sociedade colonial, e as marcas que nela deixaram. Esses estudos abrem espaço para a compreensão das experiências subjetivas do adoecimento entre escravos.

\section{Referências}

Barreto, Maria Renilda Nery. A medicina luso-brasileira: instituições, médicos e populações enfermas em Salvador e Lisboa (1808-1850). 2005. 257f. Tese (Doutorado em História das Ciências da Saúde). Casa de Oswaldo Cruz, Rio de Janeiro.

Chernoviz, Pedro Luiz Napoleão. Dicionário de medicina popular. Paris: s.ed., 1890.

DuARTE, José Rodrigues de Lima. Ensaio sobre a higiene da escravatura no Brasil. Rio de Janeiro: Typ. Universal de Laemmert, 1849.

EDLER, Flávio. A institucionalização da medicina no Brasil imperial. In: ANDRAdE, Ana Maria Ribeiro de (Ed.). Ciência em perspectiva: estudos, ensaios e debates. Rio de Janeiro: MAST/MCT-SBHC, 2003. p. 41-59.

Farias, Juliana Barreto; Gomes, Flavio dos Santos; SoAres, Carlos Eugênio Líbano. No labirinto das nações: africanos e identidades no Rio de Janeiro. Rio de Janeiro: Arquivo Nacional, 2003.

Ferreira, Luiz Otávio. Os periódicos médicos e a invenção de uma agenda sanitária para o Brasil (1827-1843). História, Ciência e Saúde - Manguinhos, Rio de Janeiro, n. 6, p. 331-351, 1999.

Florentino, Manolo Garcia. Em costas negras: uma história do tráfico de escravos entre a África e o Rio de Janeiro (séculos XVIII e XIX). Rio de Janeiro: Arquivo Nacional, 1995. Florentino, Manolo; GóEs, José Roberto. A paz nas senzalas: famílias escravas e tráfico atlântico. Rio de Janeiro: Civilização Brasileira, 1997.

Fonseca, Antônio Caetano da. Manual do agricultor dos gêneros alimentícios ou método da cultura mixta destes gêneros nas terras causadas pelo sistema vegeto-ani- 
mal; modo de criar e tratar o gado, e um pequeno tratado de medicina doméstica para fazendeiros. Rio de Janeiro: Ed. Eduardo \& Henrique Laemmert, 1863.

Freitas, Octavio de. Doenças africanas no Brasil. São Paulo: Companhia Editora Nacional, 1935.

IMBERT, Jean-Baptiste A. Manual do fazendeiro ou tratado doméstico sobre as enfermidades dos negros. Rio de Janeiro: Typ. Nacional e Const. de Seignot-Plancher e Cia., 1834.

JARDIM, David Gomes. A higiene dos escravos. 1847. 23f. Tese (Doutorado em Medicina). Faculdade de Medicina do Rio de Janeiro.

Karasch, Mary. A vida dos escravos no Rio de Janeiro (1808-1850). São Paulo: Companhia das Letras, 2000.

Kodama, Kaori. O periódico O Philantropo e o debate racial na década de 1850. Anais do III Encontro Escravidão e Liberdade no Brasil Meridional. 2007; CD-rom.

Langgaard, Theodoro J. H. Dicionário de medicina doméstica e popular. 2. ed. Rio de Janeiro: Eduardo \& Henrique Laemmert, 1873. 3 v.

Lorenzo, Ricardo de. "E aqui enlouqueceo": a alienação mental na Porto Alegre escravista, c.1843-c.1872. 2007. 263f. Dissertação (Mestrado em História). Universidade Federal do Rio Grande do Sul.

ODA, Ana Maria Galdini Raimundo. O banzo e outros males: o páthos dos negros escravos na Memória de Oliveira Mendes. Revista Latinoamericana de Psicopatologia Fundamental, São Paulo, v. 10, n. 2, p. 346-361, mar.2007.

Oliveira, Saulo Veiga. O suicídio de escravos em Campinas e na província de São Paulo (1870-1888). 2007. 257f. Dissertação (Mestrado em Ciências Médicas). Universidade Estadual de Campinas.

Oliveira, Saulo Veiga; OdA, Ana Maria Galdini Raimundo. O suicídio de escravos em São Paulo nas últimas duas décadas da escravidão. História, Ciências, Saúde - Manguinhos, Rio de Janeiro, v. 15, n. 2, abr.-jun. 2008 (no prelo).

Pimenta, Tânia Salgado. Terapeutas populares e instituições médicas na primeira metade do século XIX. In: Chalhoub, Sidney; Marques, Vera Regina Beltrão; Sampaio, Gabriela dos Reis; Galvão Sobrinho, Carlos Roberto (Ed.). Artes e ofícios de curar no Brasil. Campinas: Cecult, 2003. p. 307-330.

. Escravos no hospital da Santa Casa de Misericórdia da Bahia na segunda metade do século XIX. Anais do XXIV Simpósio Nacional de História. 2007. CD-ROM.

PoRTo, Ângela. Fontes documentais do arquivo da Santa Casa de Misericórdia do Rio de Janeiro para a história do tratamento de escravos na segunda metade do século XIX. Anais do III Encontro de Escravidão e Liberdade no Brasil Meridional. 2007. CDROM. 
PoRTo, Ângela (Ed.). Doenças e escravidão: sistema de saúde e práticas terapêuticas. Rio de Janeiro: Casa de Oswaldo Cruz, 2007. CD-ROM.

Rodrigues, Raimundo Nina. Os africanos no Brasil. Brasília: Editora da UnB, 2004.

SAmpaIo, Gabriela. Nas trincheiras da cura: as diferentes medicinas no Rio de Janeiro Imperial. Campinas: Cecult, 2001.

Sigaud, Joseph François Xavier. Du climat et des maladies au Brésil. Paris: Fortin \& Masson Libraires, 1844.

SLEnes, Robert. Malungu, ngoma vem!: África encoberta e descoberta no Brasil. Luanda: Museu Nacional da Escravatura, INPC, 1995.

. Na senzala uma flor: esperanças e recordações na formação da família escrava. Brasil Sudeste, Século XIX. Rio de Janeiro: Nova Fronteira, 1999.

Sousa, Jorge Prata de. Anotações a respeito de uma fonte: os registros de óbitos da Santa Casa de Misericórdia do Rio de Janeiro, século XIX. Cadernos de Saúde Coletiva. Rio de Janeiro, n. 11, p. 33-58, 2003.

Souza, Antônio José de. Do regimen das classes pobres e dos escravos na cidade do Rio de Janeiro em seus alimentos e bebidas: qual a influência sobre a saúde. Rio de Janeiro: Typ. J. Villeneuve, 1851.

Taunay, Carlos Augusto. Manual do agricultor brasileiro. 2. ed. Rio de Janeiro: Typ. J. Villeneuve \& Comp., 1839.

TEuscher, Reinhold. Algumas observações sobre a estatística sanitária dos escravos nas fazendas de café. 1853. 12f. Tese (para verificação de diploma). Faculdade de Medicina do Rio de Janeiro.

WitTER, Nikelen. Males e epidemias: sofredores, governantes e curadores no sul do Brasil (Rio Grande do Sul, século XIX). 2007. 297f. Tese (Doutorado em História). Universidade Federal Fluminense, Niterói.

XAVIER, Regina (Ed.). História da escravidão e da liberdade no Brasil Meridional: guia bibliográfico. Porto Alegre: Editora UFRGS, 2007.

Zampa, Vivian; Kodama, Kaori. O pensamento médico e o debate sobre a escravidão e a sífilis em meados do século XIX. Anais do XII Congresso Brasileiro de História da Medicina da SBHM, 2007.

\section{Resumos}

(Fuentes y debates en torno de la salud del esclavo en el Brasil del siglo XIX)

Este artículo presenta una muestra de la reciente producción académica sobre la salud de los esclavos en Brasil y discute las tendencias actuales y debates sobre la 
cuestión. Se centra en los trabajos en curso en el ámbito de la historia y en las principales fuentes hasta ahora recogidos por la encuesta, que coordino en la Casa de Oswaldo Cruz/Fiocruz. La investigación ha organizado las fuentes en una base de datos, que pronto estará disponible.

Palabras clave: Historia de la Salud, esclavitud, bibliografía, Brasil

(Sources et débats sur la santé de l'esclave au Brésil du XIX siècle)

Ce travail présente les plus récentes productions académiques sur la santé des esclaves au Brésil et discute les tendances actuelles et les débats sur la question. Il met l'accent sur les travaux en cours dans le domaine de l'histoire ainsi que sur les principales sources recueillies par l'enquête que nous coordonnons à la Casa de Oswaldo Cruz / Fiocruz. Ces sources ont été organisées sous forme de base de données, qui sera bientôt disponible au public.

Mots clés: Histoire de la santé, esclavage, bibliographie, Brésil

Sources and debates on the health of slaves in 19th-century Brazil

This paper presents a sampling of recent academic production on the health of slaves in Brazil and discusses current trends and debates on this topic. It focuses on both the current work in the area of history as well as the main sources gathered until now by the survey, coordinated by this author at Casa de Oswaldo Cruz / Fiocruz. The project has brought together these sources and organized them into a database, soon to be made available to the public.

Key words: History of health, slavery, bibliography, Brazil

Versão inicial recebida em junho de 2008 Versão aprovada para publicação em dezembro de 2008

\section{ÂNGeLa PôRTo}

Doutora em Saúde Coletiva pelo PPG do Instituto de Medicina Social /UERJ (Universidade Estadual do Rio de Janeiro, Brasil); Pesquisadora Titular da Casa de Oswaldo Cruz /Fiocruz (Rio de Janeiro, RJ, Brasil)

Av. Brasil, 4036/404

21040-361 Rio de Janeiro, RJ - Brasil

aporto@fiocruz.br

Rev. Latinoam. Psicopat. Fund., São Paulo, v. 11, n. 4, p. 726-734, dezembro 2008 (Suplemento) 